\title{
Early assessment of seasonal forage availability for mitigating the impact of drought on East African pastoralists
}

\author{
Anton Vrieling ${ }^{\mathrm{a}, *}$, Michele Meroni ${ }^{\mathrm{b}}$, Andrew G. Mude ${ }^{\mathrm{c}}$, Sommarat Chantarat ${ }^{\mathrm{d}}$, \\ Caroline C. Ummenhofer ${ }^{\mathrm{e}}$, Kees (C.A.J.M.) de Bie ${ }^{\mathrm{a}}$ \\ a University of Twente, Faculty of Geo-information Science and Earth Observation, P.O. Box 217, 7500 AE Enschede, The Netherlands \\ ${ }^{\mathrm{b}}$ European Commission, Joint Research Centre, Institute for Environment and Sustainability, Via E. Fermi 2749, I-21027 Ispra, VA, Italy \\ c International Livestock Research Institute, P.O. Box 30709, Nairobi 00100, Kenya \\ d The Australian National University, Crawford School of Public Policy, Canberra ACT 0200, Australia \\ e Department of Physical Oceanography, Woods Hole Oceanographic Institution, Woods Hole, MA, USA
}

\section{A R T I C L E I N F O}

\section{Article history:}

Received 12 May 2015

Received in revised form 23 November 2015

Accepted 3 December 2015

Available online $\mathrm{xxxx}$

\section{Keywords:}

Drought

MODIS

NDVI time series

Phenology

Index insurance

Livestock mortality

\begin{abstract}
A B S T R A C T
Pastoralist households across East Africa face major livestock losses during drought periods that can cause persistent poverty. For Kenya and southern Ethiopia, an existing index insurance scheme aims to reduce the adverse effects of such losses. The scheme insures individual households through an area-aggregated seasonal forage scarcity index derived from remotely-sensed normalized difference vegetation index (NDVI) time series. Until recently, insurance contracts covered animal losses and indemnity payouts were consequently made late in the season, based on a forage scarcity index incorporating both wet and dry season NDVI data. Season timing and duration were fixed for the whole area (March-September for long rains, October-February for short rains). Due to demand for asset protection insurance (pre-loss intervention) our aim was to identify earlier payout options by shortening the temporal integration period of the index. We used 250 m-resolution 10-day NDVI composites for 2001-2014 from the Moderate Resolution Imaging Spectroradiometer (MODIS). To better describe the period during which forage develops, we first retrieved per-pixel average season start- and end-dates using a phenological model. These dates were averaged per insurance unit to obtain unit-specific growing period definitions. With these definitions a new forage scarcity index was calculated. We then examined if shortening the temporal period further could effectively predict most $(>90 \%$ ) of the interannual variability of the new index, and assessed the effects of shortening the period on indemnity payouts. Our analysis shows that insurance payouts could be made one to three months earlier as compared to the current index definition, depending on the insurance unit. This would allow pastoralists to use indemnity payments to protect their livestock through purchase of forage, water, or medicines.
\end{abstract}

(c) 2015 Elsevier Inc. All rights reserved.

\section{Introduction}

Climate variability causes large inter-seasonal fluctuations of rainfall across East Africa. Large parts of East Africa have two rainfall seasons per year with rains from approximately March to May - commonly referred to as 'long rains' - and the 'short rains' during October-December (Herrmann \& Mohr, 2011; Vrieling, de Leeuw, \& Said, 2013). While rainfall variability during the short rains is strongly influenced by Indian Ocean sea surface temperatures that modulate atmospheric circulation and convection (e.g. Ummenhofer, Sen Gupta, England, \& Reason,

\footnotetext{
* Corresponding author at: University of Twente - Faculty ITC, P. O. Box 217, $7500 \mathrm{AE}$ Enschede, The Netherlands.

E-mail addresses: a.vrieling@utwente.nl, c.a.j.m.debie@utwente.nl (A. Vrieling), michele.meroni@jrc.ec.europa.eu (M. Meroni), a.mude@cgiar.org (A.G. Mude), sommarat.chantarat@anu.edu.au (S.Chantarat),cummenhofer@whoi.edu (C.C. Ummenhofer).
}

2009), climatic drivers for the long rain variability are less clear (Camberlin \& Okoola, 2003; Lyon, 2014; Williams \& Funk, 2011). Irrespective of the determinants of this variability, seasonal rainfall fluctuations notoriously and frequently lead to drought conditions in the region (Hastenrath, Polzin, \& Mutai, 2007; Rojas, Vrieling, \& Rembold, 2011; Viste, Korecha, \& Sorteberg, 2013) thereby affecting large numbers of households that predominantly depend on sufficient rainfall for sustaining their livelihoods.

Pastoralist households that reside in the region's arid and semi-arid lands (ASAL) are one of the groups strongly affected by droughts. Dry years can bring about a high mortality of their livestock due to reduced forage and water availability and outbreaks of epidemic diseases, especially if adverse conditions persist during multiple seasons (Megersa et al., 2014a). Although pastoralists are a heterogeneous group in terms of wealth (Little, McPeak, Barrett, \& Kristjanson, 2008), those with already small herd sizes risk falling into persistent poverty after drought-induced livestock losses (Barnett, Barrett, \& Skees, 2008; 
Lybbert, Barrett, Desta, \& Coppock, 2004; Toth, 2015). Due to the spatially covariate nature of drought with its effects generally felt across large regions, coping mechanisms such as herd migration or local-sharing norms (Dixit, Levin, \& Rubenstein, 2013) are often inadequate to prevent adverse impacts on livelihoods. Moreover, the increased demand for limited resources in confined areas can cause violent conflicts between pastoralist groups (Detges, 2014; Raleigh \& Kniveton, 2012). Hence, given the significance of the drought hazard, efficient mitigation strategies are needed that reduce impacts of drought-related risk to pastoralists in East Africa.

One promising strategy is to offer pastoralists insurance that pays out when drought-related livestock losses occur, or alternatively prior to losses in an effort to protect against mortality. Traditional claimbased insurance would require expensive loss verification, making it an unviable option for remote pastoralists with small herds (de Leeuw et al., 2014). An alternative is index-based insurance, whereby indemnity payouts are made on the basis of a biophysical index that correlates with the losses incurred (Barnett \& Mahul, 2007; Brown, Osgood, \& Carriquiry, 2011; Leblois \& Quirion, 2013). During the past 10 years, many index-based insurance schemes were piloted in developing countries to insure households against negative weather impacts on crop yields and livestock mortality (Miranda \& Farrin, 2012). One of the critical elements for the success of such schemes is to have a low so-called 'basis risk', i.e. the risk that households do not get paid when they suffer losses and vice-versa. Because basis risk depends on the strength of the correlation between the index and losses, index selection is important. Often-used data sources for index construction include rainfall, either measured by rain gauges or estimated from satellite observations (Tapiador et al., 2012), and satellite-derived vegetation indices like the normalized difference vegetation index (NDVI: Tucker, 1979). However, after data source selection many design options remain, e.g. regarding spatial and temporal integration (de Leeuw et al., 2014), before the data source can be reliably used as an index (Brown et al., 2011).

In 2010, an index-based livestock insurance (IBLI) project was piloted in Marsabit County, northern Kenya (Chantarat, Mude, Barrett, \& Carter, 2013), and subsequently expanded to other areas of Kenya and southern Ethiopia. From the onset of the pilot phase to present, IBLI has used satellite-derived NDVI time series to construct a seasonal forage scarcity index. However, the method to translate the original NDVI series into the index has changed through the years in an ongoing attempt to reduce basis risk (Vrieling et al., 2014). In the current design, 10-daily NDVI composites from MODIS (Moderate Resolution Imaging Spectroradiometer) at $250 \mathrm{~m}$ resolution are spatially averaged per administrative unit, temporally averaged per season, and subsequently compared between years to estimate the relative seasonal forage condition per unit. Pastoralists within an administrative unit receive a payment when the index falls below a threshold, which can be specified in terms of return period (e.g. a payment is made whenever the index is less or equal to the index reading corresponding to a below-normal season with an average recurrence interval of five years). Originally for Marsabit the index was statistically fitted to household-level livestock mortality data (Chantarat et al., 2013), but because of the lack of mortality data or poorer data quality for other regions IBLI moved to a more straightforward 'forage scarcity contract' that uses the NDVIderived index and its temporal characteristics directly. Although the evaluation of basis risk in these contracts requires validation, we can already envisage further index improvements merely from a remote sensing perspective (e.g., see the discussion in Vrieling et al., 2014). One such improvement has become more urgent following repeated demand by pastoralist groups for earlier indemnity payouts after the onset of drought events.

Payouts to insured pastoralist households can only be made after the season for which the index is calculated is concluded. Until recently, potential payout periods were fixed in March and October, because the two temporal windows used for temporal averaging were defined as the coupled long rains-long dry season (LRLD: March-September) and the coupled short rains-short dry (SRSD: October-February) season (Chantarat et al., 2013). However, inclusion of the full dry periods (approximately July-September for LD and January-February for SR) implies that livestock suffer forage scarcity for a longer period in case of a failed rainy season, and may have died before a payout is made. Therefore, this scheme financially compensates losses and allows pastoralists to replace dead animals, rather than creating options for pastoralists to protect animals through purchase of fodder, water, or medicines or other costly mitigating interventions. Noting that biomass (i.e. forage) is not developing during the dry periods and consequently NDVI provides limited information about forage conditions in these periods (Vrieling et al., 2014), good scope exists to shorten the temporal windows without losing valuable information on seasonal forage availability. An effective approach to better define the period of forage development across the season is to estimate season start- and enddates directly from temporal NDVI profiles by analysing vegetation green-up and decay using phenological analysis (Meroni, Verstraete, Rembold, Urbano, \& Kayitakire, 2014; Vrieling, de Beurs, \& Brown, 2011).

The goal of this paper is to achieve a better identification of the temporal integration period for IBLI's forage scarcity index, which can result in earlier insurance payouts to pastoralists. For this purpose, we first estimated location-specific season start- and end-dates from phenological analysis of NDVI time series. Subsequently we evaluated if end-dates can be brought forward further in time while retaining good predictability of end-of-season index variability.

\section{Study area and data}

The study area comprises a total of 131 spatial units, which are the current insurance units used in the IBLI project. The units cover nine Kenyan counties (Baringo, Garissa, Isiolo, Mandera, Marsabit, Samburu, Tana River, Turkana, and Wajir) and the Borana zone of southern Ethiopia (Fig. 1). They are based on administrative boundaries, but a number of adjustments were made in collaboration with local stakeholders to better reflect agro-ecological conditions and rangelands utilized by households residing in the unit. The unit size is variable ranging from approximately $100 \mathrm{~km}^{2}$ to $13,000 \mathrm{~km}^{2}$ (average $3000 \mathrm{~km}^{2}$ ) with smaller units principally located in Baringo county. Based on a 30-year TAMSAT rainfall climatology (Tropical Applications of Meteorology using satellite and ground-based observations: Maidment et al., 2014 ) the study area has an average annual rainfall between 150 and $500 \mathrm{~mm}$, the only exceptions being Baringo County $(\sim 700 \mathrm{~mm})$ and the west part of Borana $(\sim 550 \mathrm{~mm})$. Most inhabitants of the study area depend on livestock for their livelihood, although crop cultivation is increasingly important in the relatively wetter areas as a diversification strategy (Rufino et al., 2013). In the drier parts, the more drought-resistant camels and goats are the dominant livestock species, whereas in wetter parts cattle and sheep prevail. Given the recurrent droughts in the region, pastoralists are also shifting their livestock portfolios to include the more drought-hardy camel and goats (Boru, Schwartz, Kam, \& Degen, 2014; Megersa et al., 2014b).

The NDVI time series used in this study is the eMODIS product that the United States Geological Survey (USGS) produces from MODIS data acquired by the Terra satellite, currently operationally used in IBLI. The eMODIS product consists of 10-day maximum value NDVI composites at $250 \mathrm{~m}$ resolution (Jenkerson, Maiersperger, \& Schmidt, 2010). Although the composites are produced every five days resulting in six temporally overlapping composites per month, we only used the composites for day $1-10,11-20$, and 21-last day of each month. To reduce remaining atmospheric effects that degrade the NDVI signal (e.g., clouds), USGS applies a temporal smoothing operator, a standard technique for pre-processing NDVI time series. The operator used for the eMODIS product is the Swets algorithm; for each pixel time series a weighted least-squares regression is applied to a moving temporal window assigning largest weights to local peaks in the NDVI profile, 


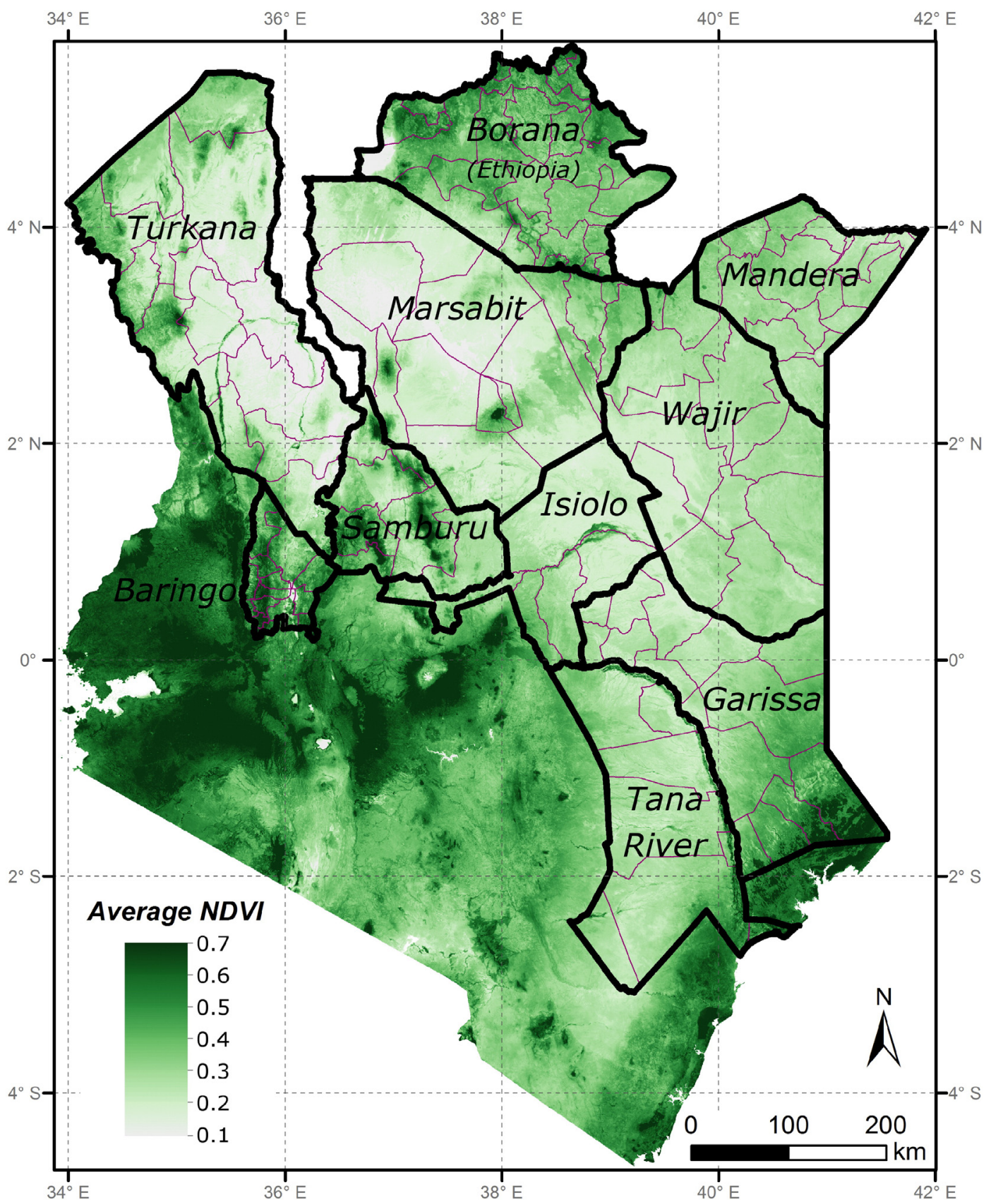

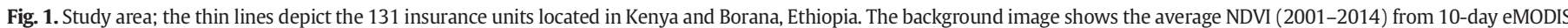
composites. For spatial reference, the image extends south to cover the entire Kenyan territory.

and smallest weights to local valleys (Swets, Reed, Rowland, \& Marko, 1999) and resulting in multiple regression lines for each data point. Averaging these lines for each point and interpolating between data points results in a continuous smoothed NDVI profile. We used the filtered eMODIS data for the East Africa window from March 2001 to September 2014, covering precisely 14 LRLD (March-September) and 13 SRSD (October-February) seasons.

\section{Methods}

\subsection{Phenological analysis from NDVI series}

Phenology is the study of the timing of biological events. In relation to satellite observations, the term "land surface phenology" is frequently used to refer to the analysis of spatial-temporal patterns of vegetation development (de Beurs \& Henebry, 2005). In this study we applied phenological analysis of NDVI series to estimate location-specific start-ofseason (SOS) and end-of-season (EOS) with the aim to describe the key period when forage biomass develops. Many approaches exist to perform phenological analysis from NDVI time series (de Beurs \& Henebry, 2010). In this study, we chose the approach recently published by Meroni et al. (2014), which is well capable of dealing with the bimodal seasonality common to East Africa. The processing steps performed independently on each pixel include:

1) For the entire eMODIS NDVI time series, we evaluated if at least $60 \%$ of the 10-day composites had valid NDVI values for land (between 0.0 and 1.0) and if the dynamic range (here taken as the difference between the 95th and 5th percentile of the time series values) was at least 0.10 . If these conditions were not met, the pixel was masked out. 
2) We assessed the seasonality of the NDVI time series (i.e. uni- or bimodal). To achieve this, we deviated from the original description by Meroni et al. (2014). Whereas they used an autocorrelogram, here we applied a Lomb normalized periodogram (Scargle, 1982) to evaluate the pixel's power spectrum and the ratio between the power associated to an annual single and double frequency. Comparing visually a large number of NDVI temporal profiles with this ratio, a threshold value of 6 was selected below which a pixel was labelled as bimodal. The periodogram was preferred to the autocorrelogram as the latter failed to detect the correct seasonality when the NDVI time series showed poor periodicity (i.e., lack of a dominant evolution pattern throughout the years) or predominance of one of the two growing seasons.

3) Multi-annual median values for each 10-day period were calculated. Based on the 'median year' and the estimated seasonality, the NDVI minima were set as breakpoints between seasons. To remove local minima, the 'median year' is iteratively smoothed until the number of breakpoints matches the expected seasonality. This is achieved through applying a weighted moving average filter that assigns larger weight to central values.

4) For each individual season, i.e. the NDVI values falling between two breakpoints, a parametric double hyperbolic tangent model was fitted to the data.

5) SOS was then estimated as the moment when the fitted NDVI model for the season exceeded $20 \%$ of the local growing amplitude (i.e. between minimum NDVI before green-up and maximum NDVI of that season), and EOS when it falls below $80 \%$ of the decay amplitude (i.e. between maximum NDVI of the season and the following minimum NDVI after decay).

Several thresholds have been proposed to obtain SOS and EOS estimates from the amplitude of vegetation index time series ranging from $10 \%$ to $50 \%$ depending on the phenological event and vegetation type targeted (e.g. Jönsson \& Eklundh, 2002; White, Thornton, \& Running, 1997). With the objective of accumulating the NDVI over the season to get a proxy of total season biomass production (Section 3.2), we set the SOS and EOS thresholds to $20 \%$ and $80 \%$ of the amplitude range in order to cover the part of the season when most of the biomass production occurs. While we acknowledge that a particular threshold choice is to some degree arbitrary, the sensitivity of the threshold choice on the biomass proxy is relatively low, because 1) it affects the period for which NDVI is averaged at moments (i.e., the beginning and end of season) when NDVI is small and has limited temporal variability compared to the central part of the season, thus providing a relatively small contribution to the seasonal value, and 2) the same thresholds are applied for the entire analysis, allowing a consistent relative comparison between the seasonal indices.

The NDVI phenological analysis resulted per pixel in a 14-year time series of season-specific SOS and EOS values. Given the dominance of bimodal seasons across the study area, we used these values to calculate the multi-annual average and standard deviation of SOS and EOS estimates per pixel for each season (long and short rains). For each insurance unit $(U)$, we then computed the spatial average of these measures by considering all pixels for which bimodality was detected inside the unit. This gave per unit the average SOS and EOS estimate as well as its (temporal) standard deviation. With the aim of setting a fixed temporal window for which the index is to be computed, we widened the temporal range defined by the average SOS and EOS estimate to take into account possible earlier [later] than average start [end] of seasons. For this purpose we considered the information provided by the temporal standard deviation of the two events for each unit as a measure of the interannual variability of the seasonality. To define the time period to be used, two constraints were considered. First, widening the window has the desired effect of including earlier (or later) than usual growing seasons but also the undesired effect of including more out-of-season signal. Second, widening the temporal window should not result in an overlap between the end and the start of two consecutive seasons for any spatial unit. This latter condition was satisfied by subtracting half a standard deviation from the area-average SOS estimate and adding half a standard deviation to the EOS estimate. We finally translated the resulting dates into a number from 1 to 36 , reflecting the 10-day period (or: dekad) that the date represents, i.e. 1 being 1-10 January. We further refer to these adjusted unit-specific 10-day periods as $\operatorname{SOS}_{U}^{*}$ and $\operatorname{EOS}_{U}^{*}$ (where the asterisk refers to the adjustment and $U$ to the insurance unit).

\subsection{Forage scarcity index calculation}

The forage scarcity index indicates how forage conditions for a specific season compare to the multi-annual average conditions and is computed with the processing steps summarized in Fig. 2. First, per insurance unit, a spatial average $\left(N D V I_{U}^{t}\right)$ for each 10-day time step $t$ is calculated from each NDVI composite (Fig. 2b). For computing $N D V I_{U}^{t}$, we excluded all pixels for which the phenological analysis found no clear seasonality (Section 3.1). These generally correspond to extremely arid areas with limited forage presence. Pixels with unimodal seasonality were retained however, as these may constitute important sources of forage. We can write this step as:

$\operatorname{NDVI}_{U}^{t}=\sum_{p=1}^{p=N} \operatorname{NDVI}_{p}^{t} / N, \quad \mathrm{p} \in U$

where $p$ is one of the $N$ pixel locations within unit $U$ for which the phenological analysis gave a uni- or bimodal seasonality. Using unit-specific $\operatorname{SOS}_{U}^{*}$ and $\operatorname{EOS}_{U}^{*}$ (Section 3.1) we then performed temporal averaging of the spatial aggregates (Fig. 2c) resulting in a seasonal average NDVI per unit (Fig. 2d), i.e.:

$N D V I_{U}^{S}=\sum_{t=S O S_{U}^{*}}^{t=E O S V I_{U}^{t}} / T$

where $s$ represents a long rain or short rain season in a specific year, and $T$ is the total number of time periods $t$ within that season (as defined by $\operatorname{SOS}_{U}^{*}$ and $\operatorname{EOS}_{U}^{*}$ ). To assess how $N D V I_{U}^{S}$ relates to multi-annual normal conditions, it is transformed into a z-score, using the seasonal average NDVI $\left(\overline{N D V I_{U}^{S}}\right)$ and its standard deviation $\left(\sigma\left(N D V I_{U}^{s}\right)\right)$ based on all years (Fig. 2e). This z-score indicates how many standard deviations $N D V I_{U}^{s}$ is greater or less than $\overline{N D V I_{U}^{s}}$.

$z N D V I_{U}^{s}=\frac{N D V I_{U}^{S}-\overline{N D V I_{U}^{s}}}{\sigma\left(N D V I_{U}^{s}\right)}$.

Given the dominant bimodality in the region, the average and standard deviation are calculated separately for the long and the short rain seasons.

\subsection{Predictability of the forage scarcity index before end-of-season}

To assess if $\operatorname{EOS}_{U}^{*}$ dates can be brought further forward in time, we evaluated for each unit if the temporal variability of the forage scarcity index $\left(z N D V I_{U}^{S}\right)$ can be accurately predicted before $E_{U}$. To achieve this, we adapted Eq. (2) in order to integrate $N D V I_{U}^{t}$ not merely over the full phenological cycle, but also over shorter time periods, i.e. from $S_{S} S_{U}^{*}$ until $\operatorname{EOS}_{U^{-}}^{*} t(t=1,2,3, \ldots)$. In addition to a 14 -year series of $z N D V I_{U}^{s}$ for the long rains, and 13-year series of $z N D V I_{U}^{S}$ for the short rains, we now also obtain the same series for a partial season (ps), i.e. $z N D V I_{U}^{p s}$.

Separately for the long and short rains, we applied a jackknife technique (leaving one year out at the time) to evaluate the predictability of $z N D V I_{U}^{s}$ based on $z N D V I_{U}^{p}$. For each jackknifed year, we estimated linear regression coefficients on the remaining dataset, modelling $z N D V I_{U}^{s}$ based on $z N D V I_{U}^{p s}$. For example for the long rains, jackknifing 14 times resulted in 14 predictions of $z N D V l s$ (i.e. $z \widehat{N D V I}_{U}^{S}$ ). We note that a possible 
a) NDVI image (10 day)

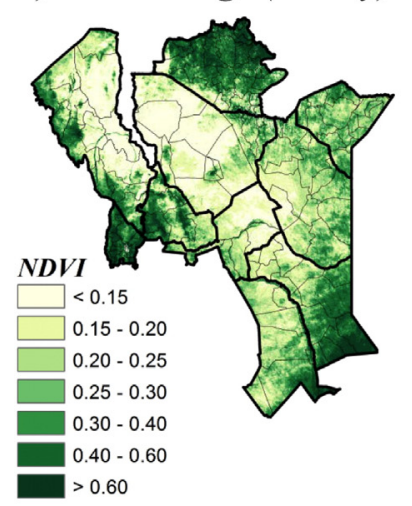

d) seasonal average NDVI

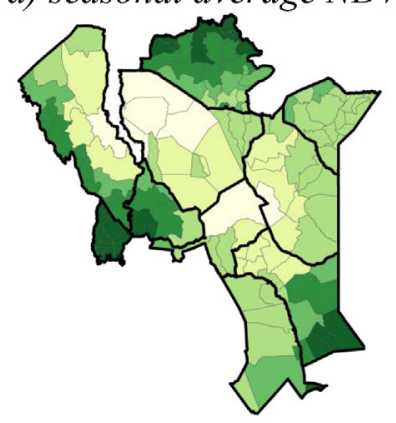

b) spatial averaging
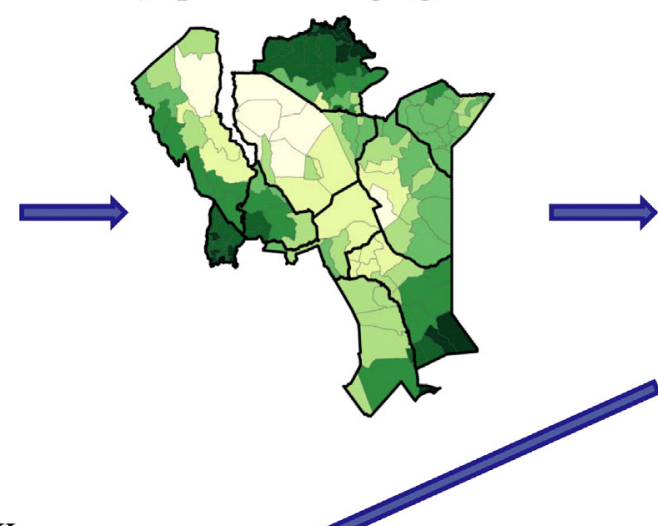

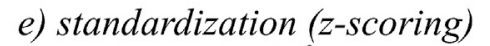

c) temporal averaging
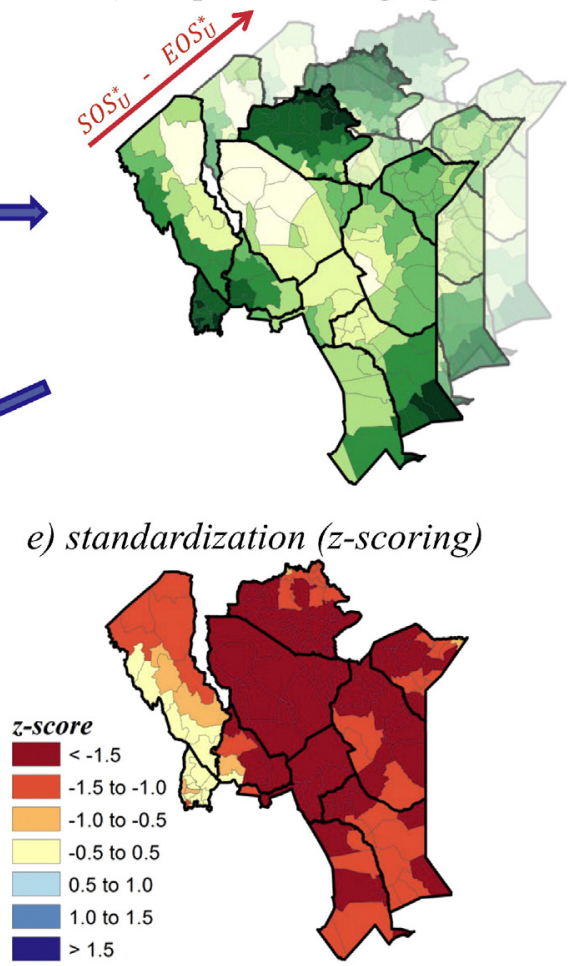

Fig. 2. Processing steps for obtaining the forage scarcity index.

alternative approach towards shortening the season only focusing on lefttail drought events (that would translate into indemnity payouts) would result in too few data points per unit; hence we focus on the full interannual index variability. We then computed the coefficient of determination between the predicted and original $z N D V l_{U}^{s}$ series as follows:

$R_{c V}^{2}=1-\frac{\sum_{s=2001}^{s=2014}\left(z N D V I_{U}^{s}-z \widehat{N D V I}_{U}^{s}\right)^{2}}{\sum_{s=2001}^{s=2014}\left(z N D V I_{U}^{s}-\overline{z N D V I}\right)^{s}}$

where $R_{c v}^{2}$ is the cross-validated coefficient of determination, and $\overline{z N D V I_{U}^{s}}$ is the multi-annual average $z N D V I_{U}^{S}$ (which is equal to 0 when considering all years based on the definition of the z-score). Rather than a simple $R^{2}$ that expresses the variance explained between $z N D V I_{U}^{s}$ and $z N D V I_{U}^{S}$, the $R_{c V}^{2}$ expresses how accurately $z N D V I_{U}^{s}$ can predict $z N D V I_{U}^{s}$ with a linear model. Following the calculation of $R_{c v}^{2}$ for all possible temporal definitions of $z N D V I_{U}^{s}$, we then determined per insurance unit the earliest 10-day period when $R_{c v}^{2}$ was greater than 0.90 . We refer to this period here as $\operatorname{EOS}_{U}^{* 90}$. The threshold value of 0.90 was selected as it represents a highly accurate prediction, within $10 \%$, of the interannual $z \mathrm{NDVI}_{U}^{S}$ variability.

\subsection{Implications for indemnity payouts}

To evaluate the effect of shortened integration periods on indemnity payouts, we apply a simple insurance model to both the $z N D V I_{U}^{S}$ and the $z N D V I_{U}^{s}$ series that use the $\operatorname{EOS}_{U}^{* 90}$ definitions for each unit. The model calculates the indemnity payout $P$ (as percentage of the insured amount) as a function of the $z N D V I_{U}^{s}$ (or $z N D V I_{U}^{S}$ ). It can be written as:

$P= \begin{cases}100, & \text { if } z N D V I_{U}^{S}<\text { exit } \\ 100 *\left(\text { trigger }-z N D V I_{U}^{S}\right) /(\text { trigger }- \text { exit }), & \text { if trigger }>z N D V I_{U}^{S}>\text { exit } \\ 0, & \text { if } z N D V I_{U}^{S}>\text { trigger }\end{cases}$ where the trigger is the $\mathrm{z}$-score threshold below which the insurance starts to pay, and exit is the z-score level corresponding to maximum payment (100\%). To set trigger and exit levels, we translated the return period to a corresponding z-score. Following IBLI's current implementation, we set exit as a one-in-hundred seasons event $(z=-2.326)$ and trigger as a one-in-five seasons event $(z=-0.842)$ and evaluated the extent to which indemnity payouts varied between the $z N D V I_{U}^{S}$ and the $z N D V I_{U}^{p s}$ series, taking payouts based on $z N D V I_{U}^{S}$ as the reference. In addition, we assessed how sensitive corresponding payment decisions and amounts were to varying trigger levels.

\section{Results}

\subsection{NDVI-derived start- and end-of-season}

Bimodal seasonality is dominant across the study area (90\% of pixels: Fig. 3a). Out of the 131 insurance units, only four units have more pixels (between 6 and 28\%) with identified unimodality as compared to bimodality. These are all small-sized units $\left(<700 \mathrm{~km}^{2}\right)$ located in Baringo county. In this region, rainfall-based seasonality analyses also found a complex spatial pattern of uni- and bimodality (Herrmann \& Mohr, 2011). No seasonality was found for $6 \%$ of all pixels concentrated in hyperarid regions around Lake Turkana, i.e. in Turkana and in Marsabit (Chalbi Desert). These regions were in fact masked due to their very small NDVI dynamic range.

The long rains growing season extends on average from early April (Fig. 3b) to early July (Fig. 3c), and the short rains from mid-October (Fig. 3e) to late January (Fig. 3f). Important deviations from this average exist. For example, the short rains start earlier (late August, early September) in higher-elevation zones of Baringo, Borana, and Turkana (Fig. 3e). Another example is the much later end of the long rains close to the Indian Ocean coast in Garissa (Fig. 3c). The start- and enddates and their spatial patterns show reasonable agreement with other phenological retrievals from coarser-resolution NDVI series (Meroni et al., 2014; Vrieling et al., 2013), although our current results 

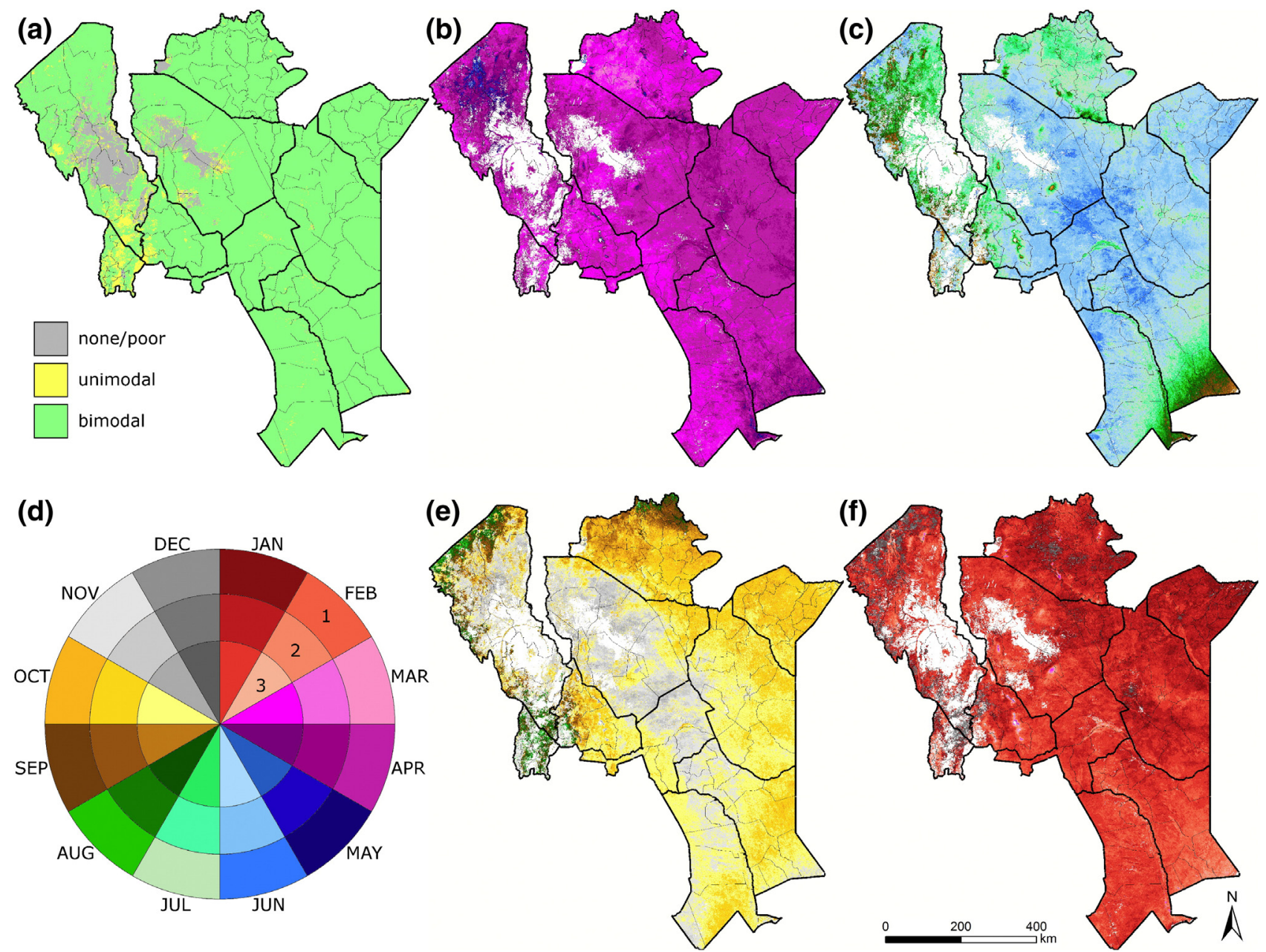

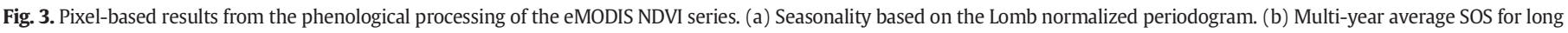

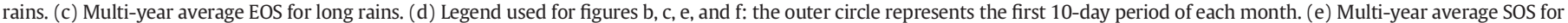
short rains. (f) Multi-year average EOS for short rains.

offer more spatial detail and attain spatially-consistent retrievals for a larger part of the study area. In the absence of ground observations of vegetation phenological development, detailed validation of our results (as for example performed by White et al., 2009) is not possible; however, the seasonality and mean phenology retrieved by the algorithm were judged to be plausible by experts and field technicians at the International Livestock Research Institute, and are consistent with the typical seasonal calendars for north-eastern Kenya and southern Ethiopia from the Famine Early Warning System Network (FEWS-NET, 2015a, 2015b). For clarity, we stress that SOS is estimated here as the moment when $20 \%$ of the local growing amplitude is exceeded. Because in water-limited conditions vegetation green-up does not start until after rains have raised soil moisture content needed for plant growth, rainfall onset can be up to one month ahead of our SOS estimates, depending on precise onset definitions used (Vrieling et al., 2011, 2013).

\subsection{Earlier assessment of forage conditions from season predictability analysis}

The period between $\operatorname{SOS}_{U}^{*}$ and $\operatorname{EOS}_{U}^{*}$ (Figs. 4a,b,d,e) is on average slightly longer than for the pixel-based results of Fig. 3, because we account for variability in the start- and end-of-season using the spatial average of the pixel-specific temporal standard deviation. We note 1 ) that the phenology-derived seasonal window to be used for temporal averaging deviates considerably from the March-September (LRLD), and
October-February (SRSD) used previously in IBLI, and 2) that the seasonal window is not uniform across the study area. For the long rains, for almost all units, the window falls within the LRLD definition. $S O S_{U}^{*}$ ranges between mid-March and late-April (Fig. 4a), while $\operatorname{EOS}_{U}^{*}$ has a greater spatial heterogeneity, i.e. from mid-June to late-August (Fig. 4b). For the short rains, we find that $S_{S} S_{U}^{*}$ displays a much larger spatial variability ranging from mid-August in Baringo and northern Borana (i.e. before October that is defined as the start for SRSD) to early November in Marsabit (Fig. 4d). The $\operatorname{EOS}_{U}^{*}$ of the short rains shows less spread, all falling between mid-January and mid-February (Fig. 4e). Following Eq. (2), we used the $\operatorname{SOS}_{U}^{*}$ and $\operatorname{EOS}_{U}^{*}$ to create unitspecific series of $z N D V V_{U}^{s}$.

Although for most units the $\operatorname{SOS}_{U}^{*}$ and $\operatorname{EOS}_{U}^{*}$ definitions span a shorter temporal averaging window as compared to the LRLD/SRSD definitions, $E_{U} S_{U}^{*}$ can be brought further forward in time. Fig. $4 \mathrm{c}$ and $\mathrm{f}$ depict the $\operatorname{EOS}_{U}^{* 90}$ for the long and short rains respectively, i.e. the earliest 10-day period when $90 \%$ of the variance in $z N D V I_{U}^{S}$ is predicted by $z N D V V_{U}^{p S}$ (with $z N D V I_{U}^{p S}$ obtained from temporal averaging between $S_{O} S_{U}^{*}$ and $E O S_{U}^{* 90}$ ). For the long rains, the end of the temporal integration period can be brought forward to as early as early- or mid-May for counties like Wajir, up to late-July for other areas (e.g. western Turkana, southern Garissa; Fig. 4c). In the spatial dimension, $\operatorname{EOS}_{U}^{* 90}$ is strongly and positively correlated with $\operatorname{EOS}_{U}^{*}$ for the long rains $(r=0.90)$. The spatial relationship between $\operatorname{EOS}_{U}^{*}$ and $\operatorname{EOS}_{U}^{* 90}$ is less strong for the short rains $(r=0.52)$, probably partly due to the smaller $\operatorname{EOS}_{U}^{*}$ variability as compared to that of the long rains. The end date of the short-rain temporal 


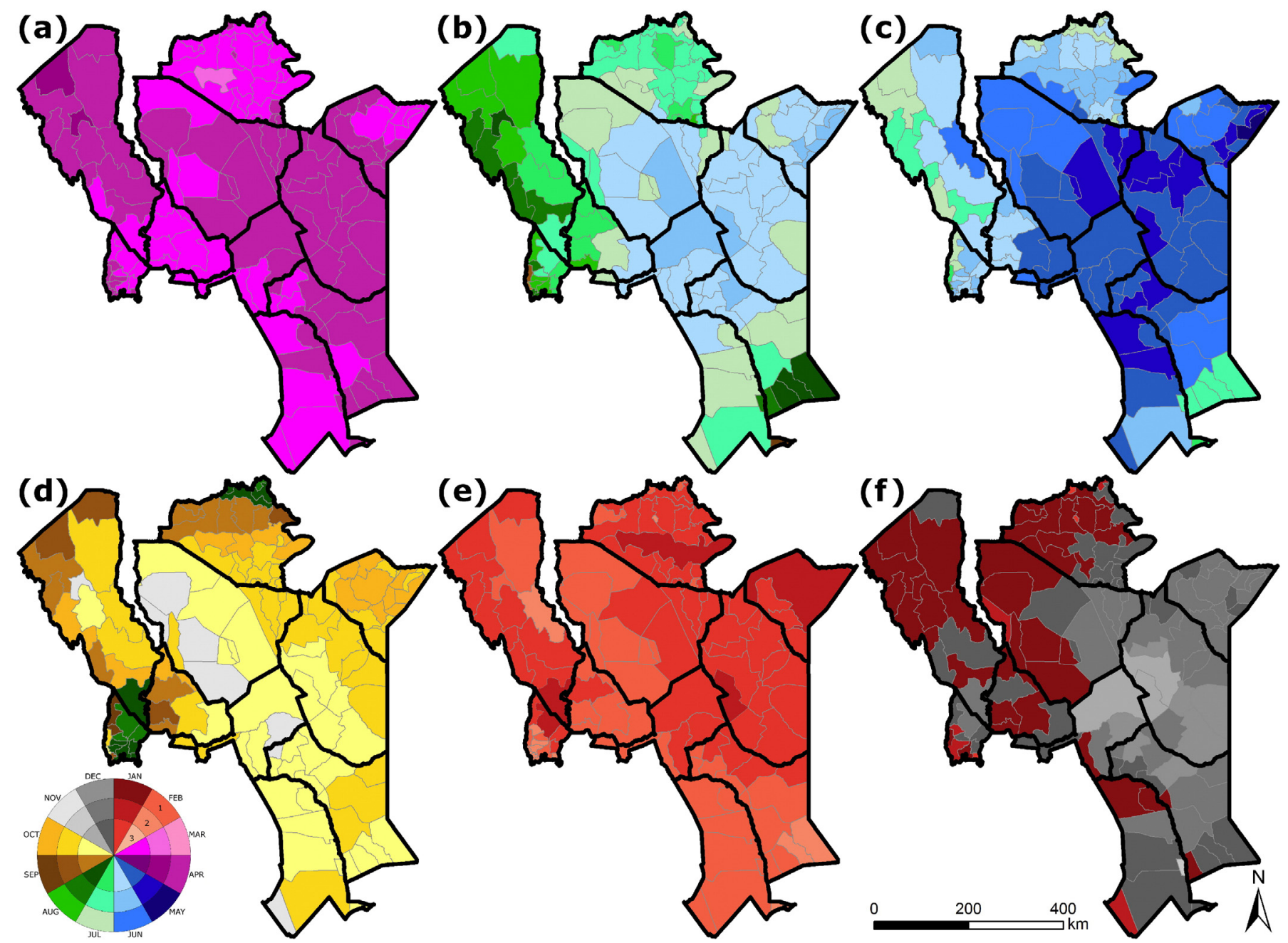

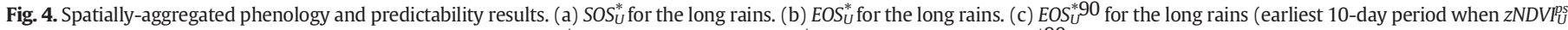

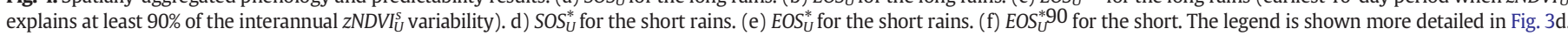

integration period can be brought forward to late-November (parts of Isiolo and Wajir) to mid-January (e.g. southern Baringo; Fig. 4f).

Temporal graphs (Fig. 5) provide a better insight into local dynamics. For Central Wajir (Fig. 5a) the NDVI temporal profiles show clear bimodal seasonality for the median, 15 th percentile, and three individual years. The short rains are on average the season with stronger forage development, judging from the larger NDVI values. The clearly-defined dry seasons are excluded from the phenology-derived temporal integration period (grey bars). Particularly for the short rains, much of the $z N D V I_{U}^{s}$ variability can be explained long (1.5 months) before the $\operatorname{EOS}_{U}^{*}$ (black bars). Wamba (Fig. 5b) is wetter than Central Wajir (larger NDVI values) and the seasons when forage develops are longer. The NDVI temporal profile likewise shows clear bimodal seasonality, although the NDVI increase in August 2007 suggests off-season rainfall. Gomole (Fig. 5c) is comparable to Wamba, the main difference being the shorter dry period between the long and short rains, resulting in a later $E_{U} S_{U}^{*}$ for the long rains, and an earlier $\operatorname{SOS}_{U}^{*}$ for the short rains. Finally, Kapedo in the southern tip of Turkana (Fig. 5d) illustrates that some units have complex seasonal patterns that may not be easily captured by the phenological analysis. For Kapedo, we found bimodal seasonality for the majority of pixels contained in the unit ( 50 vs $42 \%$ for unimodal, see also Fig. 3a). While the identified seasonality seems to fit the intermediate year (2005), the other years do not follow this bimodal pattern. For 2011 three moments of green-up can be identified, the last one starting in November, i.e. in the middle of the phenology-derived short rainy season. On the other hand, 2009 shows a complete failure of the short rains, but an early green-up before the following long rains, i.e. already in December. The here-defined optimal temporal windows (black bars) would correctly identify the short rains of 2011 as a good forage season and 2009 as a poor forage season. However, offering an insurance contract based on these seasonal parameters would require more field research in places like southern Turkana and Baringo on what pastoralists see as key moments of the year when lack of rain and/or forage development affects their livestock.

IBLI's original forage index, using LRLD and SRSD as integration periods, can be explained to a varying extent by $z N D V I_{U}^{s}$ with temporal integration from $\operatorname{SOS}_{U}^{*}$ to $\operatorname{EOS}_{U}^{* 90}$ (Fig. 6). For many units, the temporal variability is highly similar for both forage indices; $79 \%$ of the units for the long rains, and $82 \%$ for the short rains have a $R_{c v}^{2}$ above 0.75 . Particularly for the units with the strongest reduction of integration times, the $R_{c v}^{2}$ is large (Fig. 6c). This implies that for units with clearly-defined seasonality, incorporation of the dry season for temporal integration adds little information to the forage scarcity index. In itself, this is good news for Marsabit and Wajir where IBLI has been active for several years, because a shift to the new integration periods proposed in this paper would not result in large discontinuities in expected payouts. For units where the length of the new integration period is closer to the original LRLD/SRSD length, the $R_{c v}^{2}$ is often smaller, particularly for the SRSD season. For the short rains, this is particularly evident in locations like Baringo County and Kapedo (Fig. 5d) that have strongly deviating season definitions, e.g. in terms of $\operatorname{SOS}_{U}^{*}$. We stress, however, that the LRLD/SRSD integration periods are not our optimal benchmark 

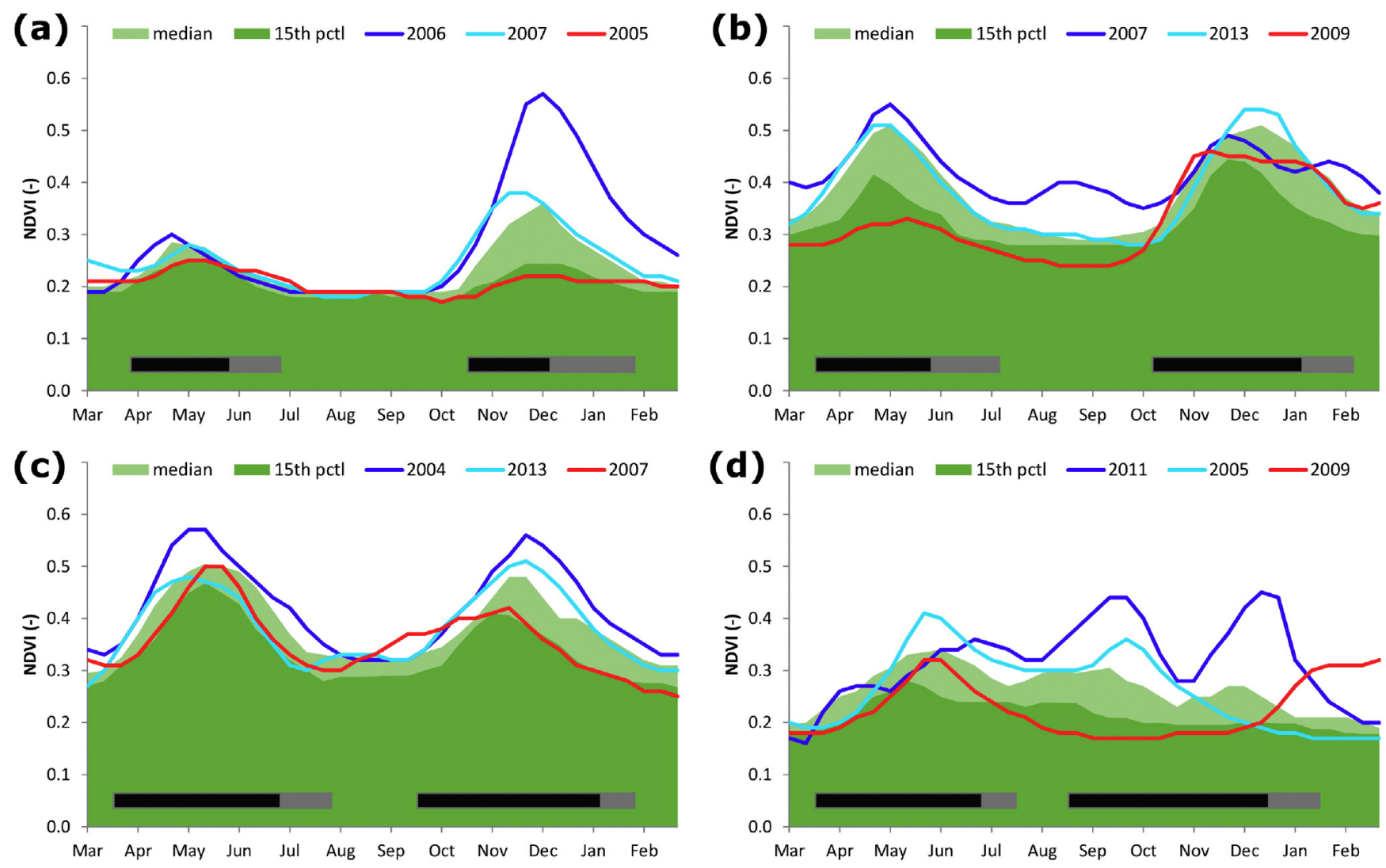

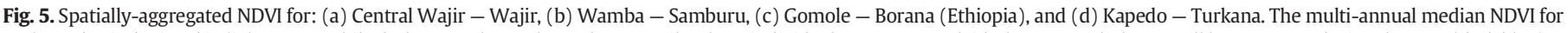

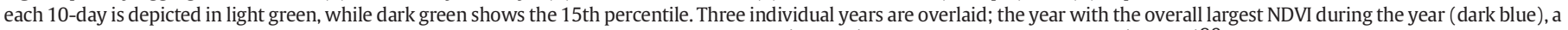
medium year (cyan), and the year with overall smallest NDVI (red). Grey bars show the $S_{O} S_{U}^{*}$ to $\operatorname{EOS}_{U}^{*}$ period, and black bars the SOS $S_{U}^{*}$ to $E O S_{U}^{*} 90$ period.

because, as we show, these fixed periods do not account for important spatial variability of seasonal parameters. Moreover the forage scarcity index should focus on the moment when forage actually develops.

\subsection{Effect of a shortened season on indemnity payouts}

Taking all insurance units and seasons together, in more than $92.5 \%$ of the cases the use of the shortened season $\left(z N D V I_{U}^{p S}\right)$ resulted in the same binary payout decision as for the reference $\left(z \mathrm{NDVl}_{U}^{S}\right)$ for any trigger level (Fig. 7a). Small indemnity amounts are the main cause of disagreement given that Type I and II errors decline with increasing return periods. For example, for a return period of five seasons, 96.5\% of binary payout decisions coincide. Excluding all unit-season combinations for which both index series resulted in no payment (dark grey part of the graph), this corresponds to $71 \%$ of all payments falling within a mere $10 \%$ payout difference, and less than $2.5 \%$ of all payments had over $25 \%$ difference in indemnity payout amount (Fig. $7 \mathrm{~b}$ ). In absolute terms, this represents 17 season-unit combinations out of 756 cases in which at least one series triggered. Setting a longer return period as a trigger results in fewer payments, of which a bigger share in relative terms have a large deviation in payout amount between the series. The $z N D V I_{U}^{p s}$ series tend to result in larger indemnity payouts than $z N D V l_{U}^{S}$, especially for larger return periods (Fig. 7b). A possible explanation could be that the shorter integration times of $z N D V I_{U}^{p s}$ capture less of
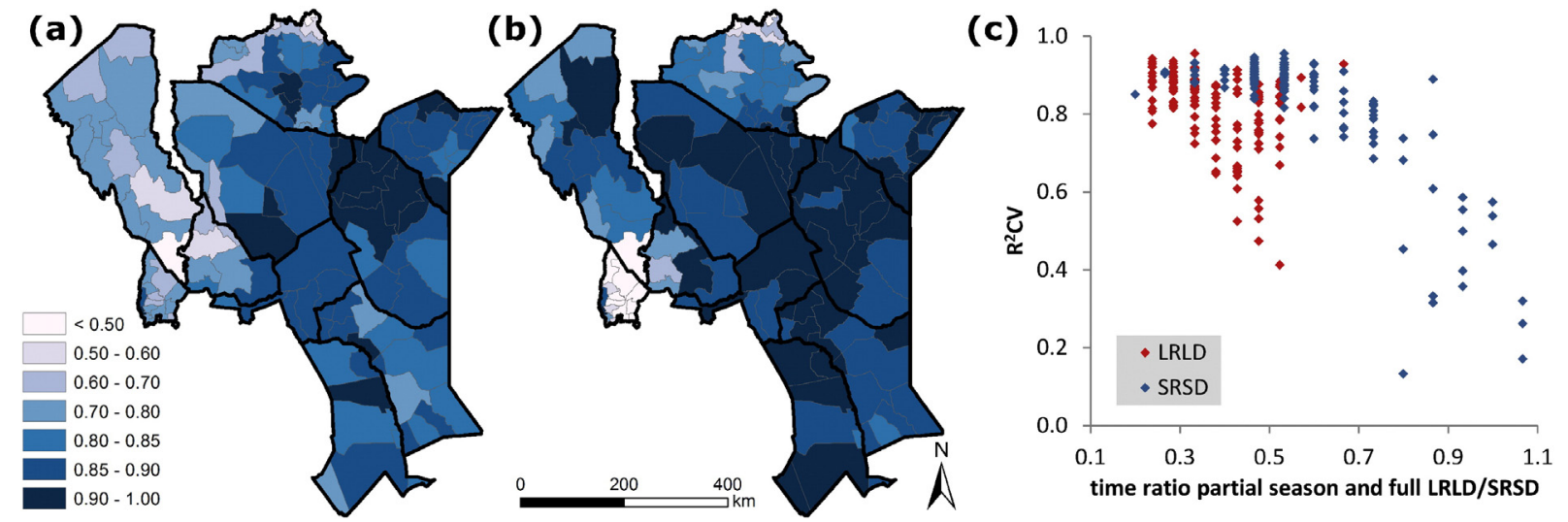

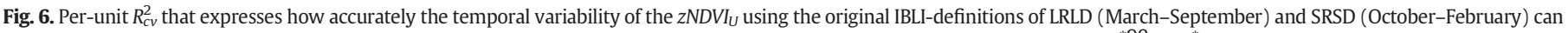

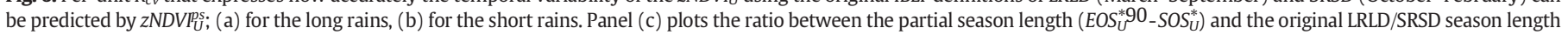
against the unit-specific $R_{c v}^{2}$. 
(a)

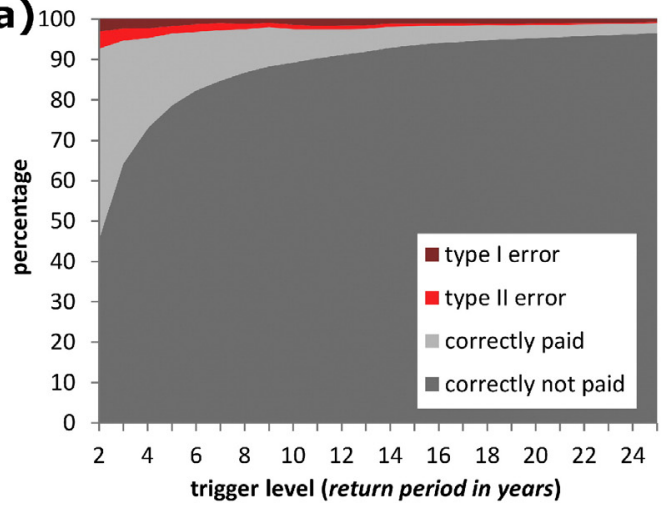

(b) 100

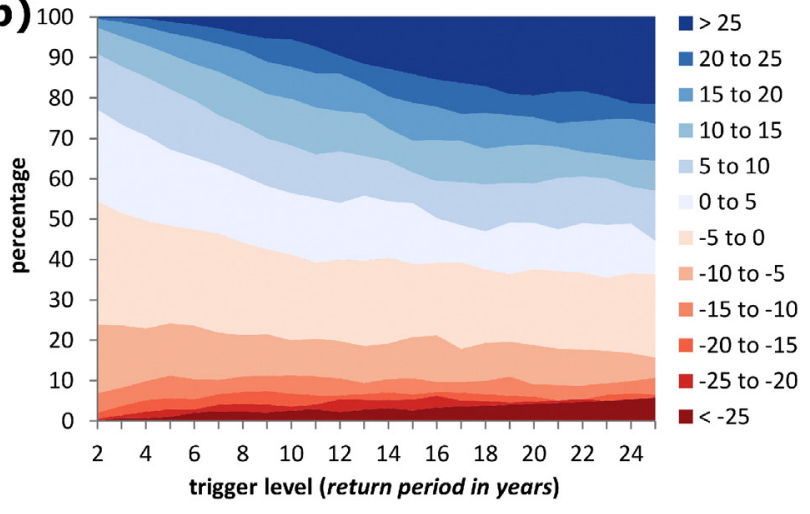

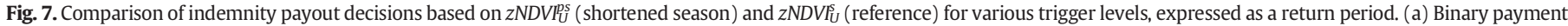

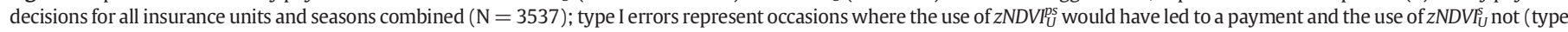

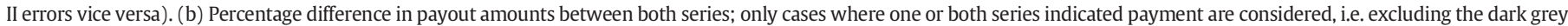
area of panel (a). Positive numbers mean that payments according to $z N D V p_{U}^{s}$ were larger than those of $z N D V l_{U}^{s}$.

the senescence phase, which in general shows smaller NDVI deviations; therefore its inclusion in $z N D V I_{U}^{S}$ makes the z-score and hence payout amounts smaller.

Fig. 8 provides a spatial overview of the main differences in indemnity payout decision and amount, based on a one-in-five season trigger and one-in-hundred season exit level. Although spatial differences occur, on average only 0.95 time per unit payment was triggered in either the $z N D V I_{U}^{s}$ or the $z N D V I_{U}^{p s}$ series, but not for both simultaneously (Fig. 8a). The largest deviation occurred in Loima (Turkana), where for seven seasons the series did not coincide; we found that this was due to small indemnities of on average $3.7 \%$.

Rather than spatially comparing pay vs. no-pay decisions that rely only on a single threshold (i.e. trigger level), differences in indemnity amounts are also relevant. We mapped these using the mean absolute error (MAE; Fig. 8b) and the mean signed deviation (MSD; Fig. 8c) calculated after removing corresponding no-pay seasons for each unit. More than $76 \%$ of all units have an MAE less than $10 \%$, indicating a close correspondence of payout amounts. Four of the 131 units (i.e. $3 \%$ ) have an MAE greater than $15 \%$, all located in Baringo. This larger MAE is likely a result of the more complex seasonality patterns in this region, whereby the $90 \%$-level predictability of $z N D V I_{U}^{s}$ based on $z N D V I_{U}^{p s}$ did not guarantee a close match of the poor seasons experienced in this county. These deviations were particularly large for the 2009 long and short seasons when June throughout December showed very small NDVI values: the shortened season excluded part of the small July/
August values (resulting in less negative z-scores) and partially excluded the out-of-season green-up the following January/February (resulting in more negative z-scores). This underlines the difficulty of defining good seasonal parameters in spatially and temporally complex areas like Baringo. The average MSD across the study area is 1.0, whereas none of the units have an absolute MSD greater than 8.8 (Fig. 8c). Overall, our results show that differences in binary payout decisions and indemnity amounts between both series are small.

\section{Discussion}

\subsection{Defining the forage production season}

Seasonality of rainfall and vegetation growth is location-dependent. This study showed that while the original IBLI seasonal definitions provide a reasonable separation of the two main seasons for most insurance units considered, important differences exist between units. Moreover, IBLI originally incorporated the dry season when defining the seasonal forage scarcity index because forage availability during that season is important for feeding livestock. Nonetheless, available forage during the dry season is generally not photosynthetically-active, hence NDVI does not detect this. For this reason, in this study we rather focus on the period when forage actually develops, as defined by SOS and EOS obtained from phenological analysis. The availability of forage in the dry season should nonetheless be a function of forage production during

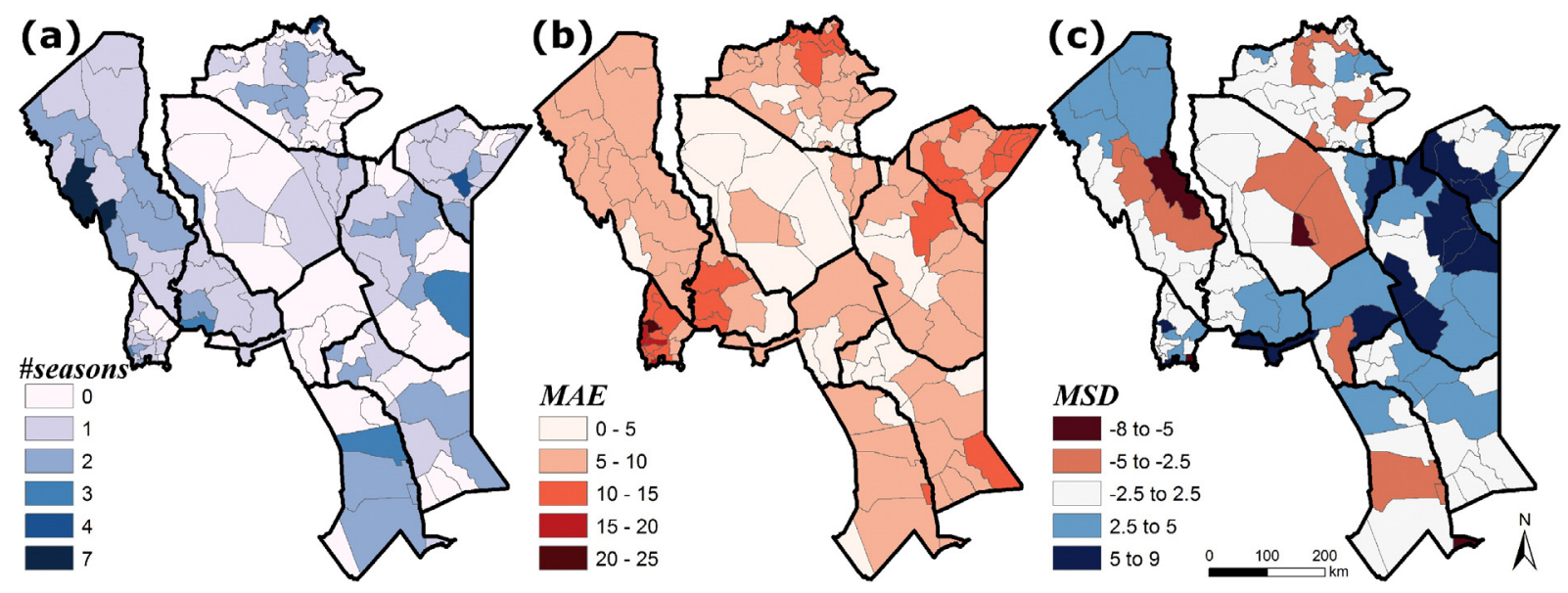

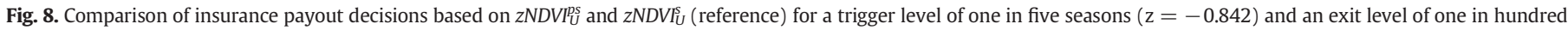

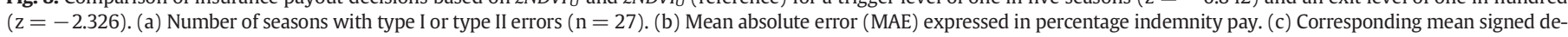
viation (MSD). For panel (b) and (c) all seasons when both series resulted in no-pay decisions for the respective unit were excluded from the calculation. 
the preceding rainy season. Although in this study we lack multi-season field data on forage biomass across the large spatial extent covered, other studies have demonstrated that the temporal integration of vegetation indices over the growing season strongly relates to the vegetation's seasonal biomass productivity (Jung et al., 2008; Rigge, Smart, Wylie, Gilmanov, \& Johnson, 2013) or derivatives like crop yield (Funk \& Budde, 2009; Meroni, Marinho, Sghaier, Verstrate, \& Leo, 2013). For that reason, we have a high level of confidence that a forage scarcity index based on seasons derived from phenological analysis provide a better measure of forage scarcity as compared to the former LRLD/SRSD definitions.

Our study concentrated on bimodal seasonality, because of its dominance across the study area (Fig. 3c). For regions with unimodal rainfall, the insurance scheme may be adapted to have a single payout moment, and hence forage scarcity index, during the year. For example, this would be more suited for the pastoralist Karamoja region in northeastern Uganda (data not shown). Without considering the dry regions with no seasonality, we observed complex seasonality patterns for Baringo and southern Turkana (Fig. 3c). Although we now forced bimodality on these regions, it is apparent that both the complex patterns and the interannual shifts in seasonality (Fig. 5d) provide a continuing challenge for effectively offering an insurance product that would respond to pastoralists' needs. This was also illustrated by the relatively larger deviations in indemnity payout amounts in Baringo between $z N D V I_{U}^{s}$ and $z N D V I_{U}^{s}$ series (Fig. $8 \mathrm{~b}$ ) predominantly resulting from an abnormal NDVI temporal development in 2009.

It is important to point out that despite our effective and spatiallyconsistent estimates of SOS and EOS, a small error may be introduced because the actual NDVI observation dates were not known (Thayn \& Price, 2008) and consequently we used the central date for each 10day composite. For the maximum-value NDVI composites used here (Section 2), it is likely that the composites used on average later dates for the green-up phase and earlier dates for the senescence phase. Not accounting for this would on average advance the SOS, and delay EOS. Whereas some NDVI products (e.g. MODIS V005) contain the perpixel observation date for each composite, for eMODIS this is not the case. To evaluate the potential effect of this, we also applied the exact methods described in Section 3.1 to $1 \mathrm{~km}$-resolution 10-day SPOT VEGETATION time series (as described in Meroni et al., 2014) for which observation dates are known and were used. We did indeed find that $\operatorname{SOS}_{U}^{*}$ was on average about 6 days earlier and $\operatorname{EOS}_{U}^{*} 2$ days later for eMODIS with respect to VEGETATION. The shift is within the 10-day sampling period and the sign of this difference is in agreement with the explanation provided above. We nonetheless decided to consistently use eMODIS in our study, given that it is the operational NDVI product now used in IBLI, and we consider the slight difference within acceptable limits.

\subsection{Operational implementation of reduced seasonal integration times}

This study showed that for most areas seasonal integration times can be substantially shortened as compared to the original LRLD and SRSD temporal definitions. Implementing the seasonal definitions (SOS $S_{U}^{*}$ to $\operatorname{EOS}_{U}^{* 90}$ ) in the IBLI insurance scheme would allow payments to be made earlier than was previously possible and thus provide pastoralists with financial resources to protect their animals from loss (Zwaagstra et al., 2010); this represents a more cost-effective and less disruptive alternative to post-mortality replacement. We note however that for several parts of the study area markets to purchase key commodities, like fodder, water, and medicine, need further development in order to fully exploit insurance as an effective animal protection mechanism (Lukuyu, Franzel, Ongadi, \& Duncan, 2011).

The unit-specific SOS $S_{U}^{*}$ to $\operatorname{EOS}_{U}^{* 90}$ found in this paper could be applied more loosely to satisfy other operational considerations. For example, for a single county uniform start- and end-dates may be chosen that roughly respect the unit-specific definitions. In fact, the here-applied
$90 \%$ threshold on the index predictability to determine $\operatorname{EOS}_{U}^{* 90}$ dates is somewhat arbitrary. A slightly smaller threshold may still qualify as a high prediction power, and explaining more than $90 \%$ is obviously acceptable as well. We demonstrated that the shortened season (using $E O S_{U}^{* 90}$ instead of $E O S_{U}^{*}$ ) resulted for most insurance units in similar payout structures with overall small MAE and MSD values.

Early payout in case of drought conditions requires rapid calculation of the forage scarcity index $z N D V I U$, i.e. shortly after the NDVI composite for $\operatorname{EOS}_{U}^{* 90}$ becomes available. Currently, USGS provides eMODIS composites approximately two to three days after the end of a 10-day period. For example, the NDVI composite for 1-10 June will be available on 13 June. Nonetheless, temporal filtering of the composite is then still necessary to reduce remaining cloud contamination (Section 2). Given that the used filter requires three 10-day periods before and after the period under consideration, an additional month of NDVI data is required. So for the example, the filtered NDVI composite for 1-10 June is available on 13 July. This implies that the final index can be obtained one month and three days after the here-reported $\operatorname{EOS}_{U}^{* 90}$ dates. Even when accounting for delays, achievable payout dates based on filtered NDVI data up to $\operatorname{EOS}_{U}^{* 90}$ are for most areas still much earlier than the end dates of IBLI's original LRLD and SRSD integration times.

\subsection{Challenges and future outlook}

Despite that large parts of the study area show clearly-separated seasons, this is not the case everywhere. Very arid landscapes (deserts) lack seasonality due to the small NDVI dynamic range (Fig. 3a), while for other areas timing of rainfall and resulting greenness varies substantially between years (Fig. 5d). It is yet unclear how effective an insurance scheme based on fixed seasonal definitions may be for such areas. Further field study is warranted to better understand how and when pastoralists are affected by weather and consequent forage conditions of key grazing areas in places like Kapedo (Turkana) and elsewhere where NDVI seasonality strongly varies between years. Offering an insurance product that does not respond to pastoralists' expectations signifies a large risk on the sustainability of the product.

An insurance scheme is only viable if it convincingly covers what it aims to cover, i.e. the scheme has a low basis risk (Miranda \& Farrin, 2012). To evaluate if low basis risk can be attained, possibly for a variety of alternative forage scarcity indices, validation is needed. In the coming years, the IBLI project intends to put substantial effort in validation and evaluation of alternative indices. Potential validation data sources can be split into four groups:

1) Long-term field observations of forage availability, such as plot-level forage biomass measurements (e.g. Roumiguié et al., 2015), timelapse photography of forage condition (Inoue, Nagai, Kobayashi, \& Koizumi, 2015; Migliavacca et al., 2011), or crowdsourcing approaches for the collection of forage condition information by pastoralists using mobile phones.

2) Household-level time series data on drought-outcome parameters like livestock mortality or the mid-upper arm circumference (MUAC), which for children indicates their nutritional status. Such data have been collected at monthly intervals by the Kenyan government from 1996 onwards in the framework of the Arid Land Resource Management Project (ALRMP; Chantarat et al., 2013) and currently by Kenya's National Drought Monitoring Authority (NDMA).

3) Drought recall exercises that exploit pastoralists' experiences to rank forage conditions across multiple seasons.

4) Alternative drought measurements such as long-term rainfall measurements from weather stations (Tapiador et al., 2012) and dendrochronological data (Gebrekirstos, Bräuning, Sass-Klassen, \& Mbow, 2014; Wils et al., 2011).

Irrespective of validation, we can envisage further improvements of the forage scarcity index, which were discussed in Vrieling et al. (2014). 
Among them, the spatial aggregation step could be improved by only incorporating pixels that constitute the key forage areas within each unit, rather than just discarding pixels with no-seasonality as we do currently. However, mapping these for large extents is not straightforward and would require pastoralists' input or alternative ways to track herd movements and pastoralists' use of their environment. Movements may also take place outside the spatial unit for which pastoralists purchased insurance, particularly during drought. Although the units used here attempt to cover the rangeland normally utilized by households residing in the unit (following interactions with local extension officers), rangeland use may be different in dry years. Nonetheless, we note that long-distance migration equally puts energetic demands on livestock thus negatively affecting their condition. This fact may support the idea that forage scarcity in the proper unit is a valid index, even if the pastoralist's herd does not continuously reside in the unit. In addition, given that drought is a covariate risk, neighbouring units are often likewise affected. Without repeating all potential index enhancements described in Vrieling et al. (2014), we argue that scope exists for further improving the forage scarcity index and that 1) validation data, in combination with 2) improved understanding of pastoralists' practices in relation to varying forage conditions are key to achieve that.

\section{Conclusions}

This study demonstrated how phenological analysis of NDVI time series can be used to obtain a location-specific estimate of season startand end-dates. We showed how these seasonal estimates could improve IBLI's forage scarcity index by incorporating only NDVI data for the period when forage is developing, while discarding the dry season. Furthermore, we found that end-of-season index variability could be accurately predicted when bringing forward season end-dates further in time. Using this shortened seasonal definition resulted in relatively small deviations in indemnity payout timing and amount throughout the study area. Our approach comprising an analysis of seasonality and index predictability could be replicated in other regions where index insurance programmes are envisaged that aim at covering shortfalls in vegetation primary productivity due to drought. The earlier assessment of the seasonal forage scarcity index identified in this study allows for earlier payouts and hence options for pastoralists to protect rather than replace their livestock. In case of drought conditions, the original IBLI approach made payments in March for the short rains and in October for the long rains. Our here-recommended season parameters allow for paying out in January/February (short rains) and July/August (long rains). These dates are already accounting for one month needed for temporal filtering of the NDVI series to suppress atmospheric effects in the data. The seasonal estimates are location-dependent; while many spatial units show the same clearly-separated seasons every year, we found that other units (predominantly in Baringo and Turkana) display lessconstant seasonality patterns. The spatial and temporal variability of NDVI seasonality in these more variable units poses continuing challenges for insurance design and delivery, as here we find the largest deviations between the original and newly-proposed forage scarcity index.

Continued efforts are needed for validating the here-proposed forage scarcity index and possible alternatives within the study area, and in other areas where livestock and forage insurance programmes may expand to. Such efforts require collaborative research with pastoralist groups who are or may become beneficiaries of these programmes in a joint attempt to reduce basis risk and provide a well-understood valuable product that may further enhance livelihoods of pastoral households in regions where resource variability strongly affects food security.

\section{Acknowledgements}

AV was funded under a contract from the International Livestock Research Institute. CCU was supported by the U.S. National Science
Foundation under grant OCE-1203892. We thank three anonymous reviewers for their useful feedback that helped to improve our manuscript.

\section{Appendix A. Supplementary data}

Supplementary data associated with this article can be found in the online version, at doi:http://dx.doi.org/10.1016/j.rse.2015.12.003. These data include the outline of the insurance units used and the start- and end-of-season dates displayed in Fig. 4 of this article.

\section{References}

Barnett, B. J., \& Mahul, O. (2007). Weather index insurance for agriculture and rural areas in lower-income countries. American Journal of Agricultural Economics, 89, 1241-1247.

Barnett, B. J., Barrett, C. B., \& Skees, J. R. (2008). Poverty traps and index-based risk transfer products. World Development, 36, 1766-1785.

Boru, D., Schwartz, M., Kam, M., \& Degen, A. A. (2014). Cattle reduction and livestock diversification among Borana pastoralists in southern Ethiopia. Nomadic Peoples, 18 $115-145$.

de Beurs, K. M., \& Henebry, G. M. (2005). Land surface phenology and temperature variation in the International Geosphere-Biosphere Program high-latitude transects. Global Change Biology, 11, 779-790.

de Beurs, K. M., \& Henebry, G. M. (2010). Spatio-temporal statistical methods for modeling land surface phenology. In I. L. Hudson, \& M. R. Keatley (Eds.), Phenological re search: methods for environmental and climate change analysis (pp. 177-208) Dordrecht, The Netherlands: Springer.

Brown, M. E., Osgood, D. E., \& Carriquiry, M. A. (2011). Science-based insurance. Nature Geoscience, 4, 213-214.

Camberlin, P., \& Okoola, R. E. (2003). The onset and cessation of the "long rains" in eastern Africa and their interannual variability. Theoretical and Applied Climatology, 75, 43-54

Chantarat, S., Mude, A. G., Barrett, C. B., \& Carter, M. R. (2013). Designing index-based livestock insurance for managing asset risk in northern Kenya. The Journal of Risk and Insurance, 80, 205-237.

Detges, A. (2014). Close-up on renewable resources and armed conflict: The spatial logic of pastoralist violence in Northern Kenya. Political Geography, 42, 57-65.

Dixit, A. K., Levin, S. A., \& Rubenstein, D. I. (2013). Reciprocal insurance among Kenyan pastoralists. Theoretical Ecology, 6, 173-187.

FEWS-NET (2015a). Ethiopia seasonal calendar: Typical year. http://www.fews.net/eastafrica/ethiopia/seasonal-calendar/december-2013 (accessed: 7 August 2015)

FEWS-NET (2015b). Kenya seasonal calendar: Typical year. http://www.fews.net/eastafrica/kenya/seasonal-calendar/december-2013 (accessed: 7 August 2015)

Funk, C., \& Budde, M. E. (2009). Phenologically-tuned MODIS NDVI-based production anomaly estimates for Zimbabwe. Remote Sensing of Environment, 113, 115-125.

Gebrekirstos, A., Bräuning, A., Sass-Klassen, U., \& Mbow, C. (2014). Opportunities and applications of dendrochronology in Africa. Current Opinion in Environmental Sustainability, 6, 48-53.

Hastenrath, S., Polzin, D., \& Mutai, C. (2007). Diagnosing the 2005 drought in equatoria East Africa. Journal of Climate, 20, 4628-4637.

Herrmann, S. M., \& Mohr, K. I. (2011). A continental-scale classification of rainfall seasonality regimes in Africa based on gridded precipitation and land surface temperature products. Journal of Applied Meteorology and Climatology, 50, 2504-2513.

Inoue, T., Nagai, S., Kobayashi, H., \& Koizumi, H. (2015). Utilization of ground-based digital photography for the evaluation of seasonal changes in the aboveground green biomass and foliage phenology in a grassland ecosystem. Ecological Informatics, 25, 1-9.

Jenkerson, C. B., Maiersperger, T., \& Schmidt, G. (2010). eMODIS: A user-friendly data source. Open-File Report 2010-1055. USGS (10 pp.).

Jönsson, P., \& Eklundh, L. (2002). Seasonality extraction by function fitting to time-series of satellite sensor data. IEEE Transactions on Geoscience and Remote Sensing, 40 1824-1832.

Jung, M., Verstraete, M., Gobron, N., Reichstein, M., Papale, D., Bondeau, A., ... Pinty, B. (2008). Diagnostic assessment of European gross primary production. Global Change Biology, 14, 2349-2364.

Leblois, A., \& Quirion, P. (2013). Agricultural insurances based on meteorological indices: Realizations, methods and research challenges. Meteorological Applications, 20, 1-9.

de Leeuw, J., Vrieling, A., Shee, A., Atzberger, C., Hadgu, K., Biradar, C., ... Turvey, C. (2014) The potential and uptake of remote sensing in insurance: A review. Remote Sensing, 6, 10888-10912

Little, P. D., McPeak, J., Barrett, C. B., \& Kristjanson, P. (2008). Challenging orthodoxies: understanding poverty in pastoral areas of east Africa. Development and Change, 39, 587-611.

Lukuyu, B., Franzel, S., Ongadi, P. M., \& Duncan, A. J. (2011). Livestock feed resources: Current production and management practices in central and northern Rift Valley provinces of Kenya. Livestock Research for Rural Development, 23, 112

Lybbert, T. J., Barrett, C. B., Desta, S., \& Coppock, D. L. (2004). Stochastic wealth dynamics and risk management among a poor population. The Economic Journal, 114, 750-777.

Lyon, B. (2014). Seasonal drought in the Greater Horn of Africa and its recent increase during the March-May long rains. Journal of Climate, 27, 7953-7975.

Maidment, R. I., Grimes, D., Allan, R. P., Tarnavsky, E., Stringer, M., Hewison, T., ... Black, E. (2014). The 30 year TAMSAT African rainfall climatology and time series (TARCAT) data set. Journal of Geophysical Research-Atmospheres, 119, 10619-10644. 
Megersa, B., Markemann, A., Angassa, A., Ogutu, J. O., Piepho, H. P., \& Valle Zaráte, A. (2014a). Impacts of climate change and variability on cattle production in southern Ethiopia: Perceptions and empirical evidence. Agricultural Systems, 130, 23-34.

Megersa, B., Markemann, A., Angassa, A., Ogutu, J. O., Piepho, H. P., \& Valle Zárate, A (2014b). Livestock diversification: An adaptive strategy to climate and rangeland ecosystem changes in southern Ethiopia. Human Ecology, 42, 509-520.

Meroni, M., Marinho, E., Sghaier, N., Verstrate, M., \& Leo, O. (2013). Remote sensing based yield estimation in a stochastic framework: Case study of durum wheat in Tunisia. Remote Sensing, 5, 539-557.

Meroni, M., Verstraete, M. M., Rembold, F., Urbano, F., \& Kayitakire, F. (2014). A phenology-based method to derive biomass production anomalies for food security monitoring in the Horn of Africa. International Journal of Remote Sensing, 35 2472-2492.

Migliavacca, M., Galvagno, M., Cremonese, E., Rossini, M., Meroni, M., Sonnentag, O., ... Richardson, A. D. (2011). Using digital repeat photography and eddy covariance data to model grassland phenology and photosynthetic $\mathrm{CO} 2$ uptake. Agricultura and Forest Meteorology, 151, 1325-1337.

Miranda, M. J., \& Farrin, K. (2012). Index insurance for developing countries. Applied Economic Perspectives and Policy, 34, 391-427.

Raleigh, C., \& Kniveton, D. (2012). Come rain or shine: An analysis of conflict and climate variability in east Africa. Journal of Peace Research, 49, 51-64.

Rigge, M., Smart, A., Wylie, B., Gilmanov, T., \& Johnson, P. (2013). Linking phenology and biomass productivity in South Dakota mixed-grass prairie. Rangeland Ecology and Management, 66, 579-587.

Rojas, O., Vrieling, A., \& Rembold, F. (2011). Assessing drought probability for agricultura areas in Africa with coarse resolution remote sensing imagery. Remote Sensing of Environment, 115, 343-352.

Roumiguié, A., Jacquin, A., Sigel, G., Poilvé, H., Lepoivre, B., \& Hagolle, O. (2015). Development of an index-based insurance product: Validation of a forage production index derived from medium spatial resolution fCover time series. GIScience \& Remote Sensing, 52, 94-113.

Rufino, M. C., Thornton, P. K., Ng'ang'a, S. K., Mutie, I., Jones, P. G., van Wijk, M. T., \& Herrero, M. (2013). Transitions in agro-pastoralist systems of east Africa: Impacts on food security and poverty. Agriculture, Ecosystems and Environment, 179, 215-230.

Scargle, J. D. (1982). Studies in astronomical time series analysis. II - Statistical aspects of spectral analysis of unevenly spaced data. Astrophysical Journal, 263, 835-853.

Swets, D. L., Reed, B. C., Rowland, J. D., \& Marko, S. E. (1999). A weighted least-squares approach to temporal NDVI smoothing. Proceedings of the 1999 ASPRS annual conference (pp. 526-536). Portland, Oregon: American Society of Photogrammetric Remote Sensing.
Tapiador, F. J., Turk, F. J., Petersen, W., Hou, A. Y., García-Ortega, E., Machado, L. A. T., ... de Castro, M. (2012). Global precipitation measurement: Methods, datasets and applications. Atmospheric Research, 104, 70-97.

Thayn, J. B., \& Price, K. P. (2008). Julian dates and introduced temporal error in remote sensing vegetation phenology studies. International Journal of Remote Sensing, 29, 6045-6049.

Toth, R. (2015). Traps and thresholds in pastoralist mobility. American Journal of Agricultural Economics, 97, 315-332.

Tucker, C. J. (1979). Red and photographic infrared linear combinations for monitoring vegetation. Remote Sensing of Environment, 8, 127-150.

Ummenhofer, C. C., Sen Gupta, A., England, M. H., \& Reason, C. J. C. (2009). Contributions of Indian Ocean sea surface temperatures to enhanced East African rainfall. Journal of Climate, 22, 993-1013.

Viste, E., Korecha, D., \& Sorteberg, A. (2013). Recent drought and precipitation tendencies in Ethiopia. Theoretical and Applied Climatology, 112, 535-551.

Vrieling, A., de Beurs, K. M., \& Brown, M. E. (2011). Variability of African farming systems from phenological analysis of NDVI time series. Climatic Change, 109, 455-477.

Vrieling, A., de Leeuw, J., \& Said, M. Y. (2013). Length of growing period over Africa: Variability and trends from 30 years of NDVI time series. Remote Sensing, 5, 982-1000.

Vrieling, A., Meroni, M., Shee, A., Mude, A. G., Woodard, J., de Bie, C. A. J. M., \& Rembold, F. (2014). Historical extension of operational NDVI products for livestock insurance in Kenya. International Journal of Applied Earth Observation and Geoinformation, 28, 238-251.

White, M. A., de Beurs, K. M., Didan, K., Inouye, D. W., Richardson, A. D., Jensen, O. P., ... Lauenroth, W. K. (2009). Intercomparison, interpretation, and assessment of spring phenology in North America estimated from remote sensing for 1982-2006. Global Change Biology, 15, 2335-2359.

White, M. A., Thornton, P. E., \& Running, S. W. (1997). A continental phenology model for monitoring vegetation responses to interannual climatic variability. Global Biogeochemical Cycles, 11, 217-234.

Williams, A. P., \& Funk, C. (2011). A westward extension of the warm pool leads to a westward extension of the Walker circulation, drying eastern Africa. Climate Dynamics, 37, 2417-2435.

Wils, T. H. G., Sass-Klaassen, U. G. W., Eshetu, Z., Bräuning, A., Gebrekirstos, A., Couralet, C., ... Beeckman, H. (2011). Dendrochronology in the dry tropics: The Ethiopian case, Trees - Structure and Function, 25, 345-354.

Zwaagstra, L., Sharif, Z., Wambile, A., de Leeuw, J., Said, M. Y., Johnson, N., ... Herrero, M. (2010). An assessment of the response to the 2008-2009 drought in Kenya: A report to the European Union delegation to the Republic of Kenya. Nairobi. Kenya: International Livestock Research Institute (ILRI) (109 pp.). 